\title{
Formation of a vesicovaginal fistula in a pig model
}

\author{
This article was published in the following Dove Press journal: \\ Research and Reports in Urology \\ 14 August 2015 \\ Number of times this article has been viewed
}

\author{
Jennifer Lindberg' \\ Emilie Rickardsson' \\ Margrethe Andersen ${ }^{2}$ \\ Lars Lund ${ }^{1,2}$ \\ 'Clinical Institute, University \\ of Southern Denmark, Odense, \\ ${ }^{2}$ Department of Urology, Odense \\ University Hospital, \\ Odense C, Denmark
}

Correspondence: Lars Lund Department of Urology, Odense University Hospital, Søndre boulevard

29, 5000 Odense C, Denmark

Tel +4551408982

Fax +45 654I I726

Email lars.lund@rsyd.dk
Objective: To establish an animal model of a vesicovaginal fistula that can later be used in the development of new treatment modalities.

Materials and methods: Six female pigs of Landrace/Yorkshire breed were used. Vesicotomy was performed through open surgery. An standardized incision between the bladder and the vagina was made, and the mucosa between them was sutured together with absorbable sutures. A durometer ureteral stent was introduced into the fistula, secured with sutures to the bladder wall, allowing for the formation of a persistent fistula tract. Six weeks postoperatively cystoscopy was performed to examine the fistula in vivo. Thereafter, the pigs were euthanized with intravenous pentobarbital.

Results: Two out of four (50\%) pigs developed persistent fistulas. No per- or postoperative complications occurred.

Conclusion: This study indicates that this pig model of vesicovaginal fistula can be an effective and cheap way to create a fistula between the bladder and vagina.

Keywords: vesicovaginal fistula, urinary fistula, animal model

\section{Introduction}

Vesicovaginal fistula (VVF) is a major problem worldwide. The majority of cases occur in developing countries, where the lack of sufficient obstetric care during obstructed labor is the most common etiology.$^{1-7}$ The prevalence of obstetric fistula appears uncertain in available literature. The most commonly mentioned estimate is 2 million women worldwide. ${ }^{8}$ This number is an old and uncertain estimate derived from an article that does not sufficiently explain how this estimate was made. According to the United Nations Population Fund (UNFPA) fistula map, 16,016 women in 43 developing countries were treated for obstetric fistulas in $2011 .{ }^{9}$ One should keep in mind that this figure only includes those women who sought medical care from the facilities included. In the industrial world, VVF is seen primarily as a complication to pelvic surgery, especially hysterectomy. ${ }^{1-7,10}$ VVF as a complication of hysterectomy for benign indications has been reported in several studies with incidence ranging from one per 1,250 to one per 333..$^{5-7,10,11}$

A VVF is traditionally treated either conservatively or surgically. The conservative approach for small fistulas has a success rate of 7\%-12.5\%. ${ }^{1,3,12}$ Larger fistulas require surgical closure and can be performed transvaginally with a success rate of $82 \%-100 \%$ or transabdominally with a success rate of $90 \% .{ }^{1,3}$ Recently, laparoscopic and robotic surgery have been developed as minimally invasive procedures. ${ }^{1,3,12}$ All the aforementioned procedures are associated with re-hospitalization and longer recovery periods, 
which substantially adds to the economic costs for society and reduces the quality of life for the individual patient. ${ }^{1,4}$

It is desirable to find new effective and less invasive treatments for VVF to reduce the personal suffering and the costs for society. The capability of stem cells to self-renew and differentiate into multiple types of specialized cells makes stem cells interesting targets for research, and positive results from the use of stem cells have been demonstrated in many medical fields. ${ }^{13-16}$ Stem cells may also play a role in repair and regeneration treatment for VVF. Before these new promising methods can be used in the treatment of VVF, they should be tested in an animal model that is transferable to man. The aim of this study was to create a VVF model in a pig.

\section{Materials and methods}

Six female pigs of Landrace/Yorkshire breed were used in this study. They were retrieved from a local farmer at an average age of 16 weeks. The experiments were conducted at a fully licensed Danish animal research laboratory and performed according to the Danish animal research law. ${ }^{17}$ Approval was obtained from the Danish Animal Experiments Inspectorate.

The pigs were stabled in a $2.8 \times 4.0 \mathrm{~m}$ booth, on an Altro safe vinyl floor with bedding of JELUXYL ${ }^{\circledR}$ HW 300/500 (JELU-WERK, Rosenberg, Germany) for 43 days. They were fed with full feed TopCross (Brødr. Ewers A/S, Aabenraa, Denmark), wrap, and apples. The pigs had unrestrained access to food and clean tap water. There was a light-dark cycle of 12 hours each and a room temperature of $21^{\circ} \mathrm{C}$. After surgery, trained animal caretakers observed the pigs a minimum of three times daily.

\section{Surgery}

The animals were sedated with intramuscular (IM) medetomidine $(0.05 \mathrm{mg} / \mathrm{kg})$ and midazolam $(0.25 \mathrm{mg} / \mathrm{kg})$. Atropin $(0.05 \mathrm{mg} / \mathrm{kg})$ was given intramuscularly to reduce airway secretion. An intravenous (IV) port was placed in an ear vein. Propofol $3.8-7.5 \mathrm{mg} / \mathrm{kg}$ was given intravenously until tail, hoof, and cornea reflexes were no longer apparent. The pigs were intubated, placed on the operation table in a supine position, and set to a respirator. Continuous inhalation anesthesia of sevoflurane $4 \%$ and inhalation of oxygen: air (1:1) was given. The pigs were monitored with electrocardiogram (ECG), pulse, blood pressure, respiration rate, and saturation. Peroperative buprenorphine $0.0075 \mathrm{mg} / \mathrm{kg}$ and prophylactic ampicillin $15 \mathrm{mg} / \mathrm{kg}$ were given.

The procedures were performed in a sterile environment. The abdomen was washed and prepped with iodine. A vertical laparotomy was performed from just below the umbilicus to the symphysis. Peritoneal opening was performed due to the intraperitoneal localization of the bladder in pigs. The bladder and the two ureters were identified. A vertical incision facing the ventral surface and lower part of the bladder was made with a length of approximately $7 \mathrm{~cm}$ and directed toward the bladder neck. Urine was collected with suction, ensuring minimum leakage.

A rectal tube (FG 18, Unomedical A/S, Greensboro, NC, USA) was placed in the vagina and palpated through the bladder and vaginal wall. This made the landmark for the incision between the two organs. The catheter was first fixated with Babcock forceps and then with a Vicryl 3.0 suture (Ethicon, Cincinnati, OH, USA). A standardized $1 \mathrm{~cm}$ long incision was made on the bladder wall over the plastic tube inserted into the animal's vagina while ensuring that the ureters and the cervix were not damaged. Four absorbable sutures were placed around the incision, at 12, 3, 6, and 9 o'clock, assembling the bladder and vaginal mucosa and creating the fistula. The rectal tube was removed. A modified Polaris ${ }^{\mathrm{TM}}$ Percuflex ${ }^{\circledR}$ Dual Durometer Ureteral stent (Boston Scientific, Marlborough, MA, USA), size 6F, $26 \mathrm{~cm}$, with one curl cut resulting in a $10 \mathrm{~cm}$ long stent, was introduced into the fistula and secured with several absorbable sutures in the bladder wall (Figure 1). The stents served the purpose of securing fistula formation. A two-layer closure of the bladder was performed with continuous absorbable sutures. The peritoneum and the abdominal muscular layer were closed with continuous absorbable sutures (PDS 0, Ethicon), followed by closure of cutis with continuous absorbable lockstitch sutures (Vicryl 1.0). Initially two pigs were used to investigate the plausibility of the surgical technique and they were euthanized with IV pentobarbital $(50 \mathrm{mg} / \mathrm{kg})$ directly after the operation.

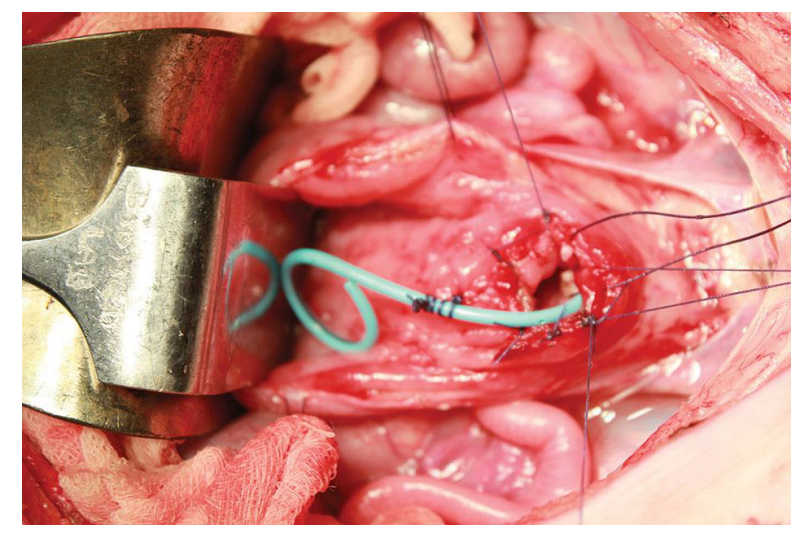

Figure I Fistula creation and placement of Percuflex ${ }^{\circledR}$ Dual Durometer Ureteral stent (Boston Scientific, Marlborough, MA, USA). 


\section{Postoperative care and control}

The remaining four pigs underwent surgery and were allowed to wake up in secluded booths. A veterinarian and trained animal caretakers observed the pigs daily. They were given analgesics (Buprenorphine $0.045 \mathrm{mg} / \mathrm{kg}$ ) three times daily for a minimum of 3 days. Ampicillin $(10 \mathrm{mg} / \mathrm{kg})$ was given once daily for 3 days. Four weeks postoperatively, the pigs were lightly sedated with medetomidine $(0.05 \mathrm{mg} / \mathrm{kg})$, midazolam $(0.25 \mathrm{mg} / \mathrm{kg})$, and atropine $(0.05 \mathrm{mg} / \mathrm{kg})$ for the purpose of a gynecologic examination, using a colonoscope, to observe whether the stents were in situ. Six weeks postoperatively, the pigs were fully sedated as described earlier. Cystoscopies were performed to examine the fistulas in vivo. Methylene blue coloring was administered into the bladder through a bladder catheter. Leakage was observed through the vagina. The pigs were euthanized under anesthesia with IV pentobarbital $(50 \mathrm{mg} / \mathrm{kg})$ with the possibility for examination of the fistulas from inside the bladder (Figure 2).

\section{Results}

The mean weight was $41.7 \mathrm{~kg}(38.7-45.4 \mathrm{~kg})$ at the start of the study. Sufficient weight gain was observed in all pigs at the end of the study (mean $34.5 \mathrm{~kg}$ [30.8-39.9 kg]), indicating healthy pigs (Table 1). Two pigs successfully developed a VVF of $5 \mathrm{~mm}$ in diameter. No postsurgical complications were observed. Recovery after operation was quick; 2 hours post surgically, all pigs had fully regained consciousness and showed no signs of pain or limitations in their natural behavior. All four pigs were seen urinating and defecating within 24 hours postoperatively. The abdominal cicatrices were observed daily for 10 days. The pigs were given analgesic and antibiotic treatment for 3 days. No sign of pain, discomfort or infection was observed; thus, no further medication was needed.

During gynecological examination, no ureteral stents were found in the top of the vaginas. However, all stents were found during cystoscopy 2 weeks later lying loose in the bladder, with encrustation on the stents. Inspection of the scars showed well-healed wounds.

\section{Discussion}

The aim of this study was to produce an animal model that later can be used to test new treatments, eg, injection of stem cells. A successful fistula was created in $50 \%$ of the pigs. The mean weight gain observed in this study was $34.5 \mathrm{~kg}(30.8-39.9 \mathrm{~kg})$. Owing to the fast growth, two pigs probably outgrew their ureteral stents, which then were displaced into the bladder. This meant that the pigs probably did not have sufficient time with the stents in

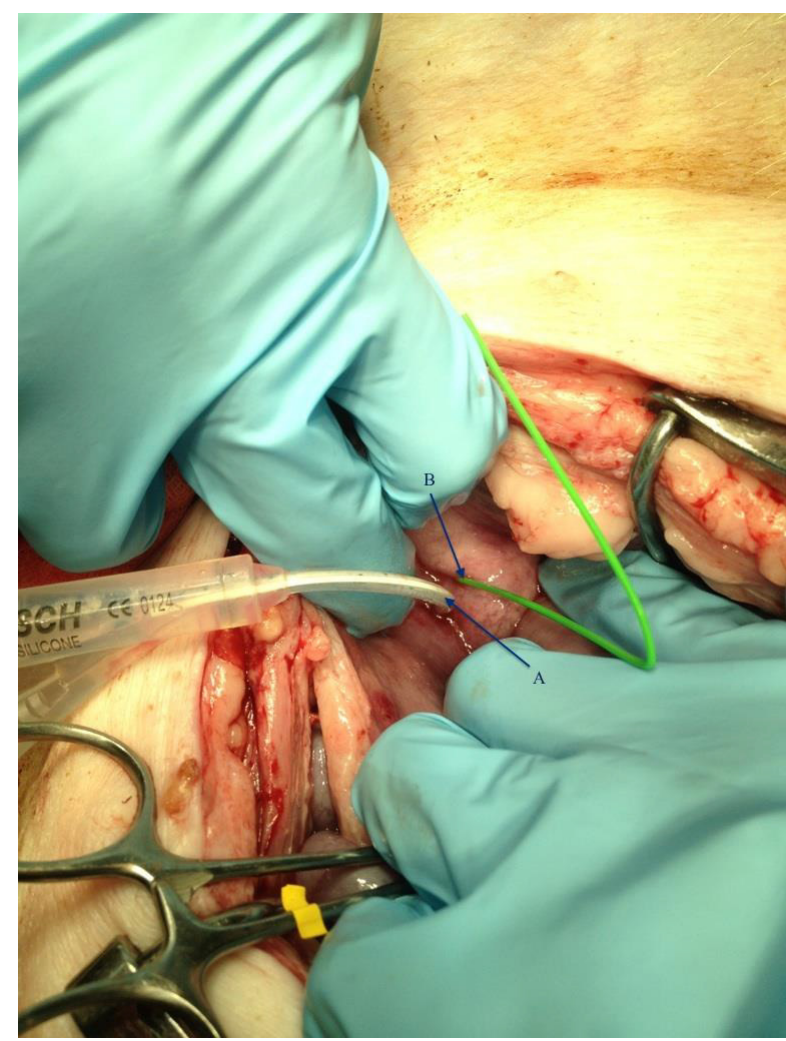

Figure 2 During autopsy, the fistulas were examined from inside the urine bladder. Notes: (A) Showing a bladder catheter inserted into the urethra. (B) Showing a wire inserted into the fistula.

the fistula which therefore probably closed. An alternative could be to use fully grown pigs, but this would require bigger facilities than ours. One end of the stents was cut to minimize any discomfort for the pigs. In future studies the ureteral stent should be fixated between the bladder and the vagina at their full length, minimizing the risk of displacement and premature closure, or a rubber catheter $\mathrm{CH} 20$ could be used. Longer stents or catheters would also make the gynecological examination easier. It was difficult to find appropriate instruments for the present task because the pig vagina is long and narrow, but examination with a colonoscope proved successful. To follow the biologic response of the treatment and possible side effects over time, it was necessary to use a living model. We are aware that the present model is created by a surgical trauma and

Table I Characteristics of the pigs

\begin{tabular}{lllll}
\hline & $\begin{array}{l}\text { Weight } \\
\text { day I (kg) }\end{array}$ & $\begin{array}{l}\text { Weight } \\
\text { day } \mathbf{4 2} \mathbf{( k g )}\end{array}$ & $\begin{array}{l}\text { Fistula } \\
\text { Yes/no }\end{array}$ & $\begin{array}{l}\text { Duration of } \\
\text { surgery (minutes) }\end{array}$ \\
\hline Pig I & 45.4 & 76.2 & Yes & 84 \\
Pig 2 & 41.6 & 76.3 & Yes & 72 \\
Pig 3 & 38.7 & 71.4 & No & 60 \\
Pig 4 & 40.9 & 80.8 & No & 90 \\
\hline
\end{tabular}


not formed by ischemia like an obstetric fistula, but that could be a goal for further development.

The results of the use of an animal model of VVF, with six female sheep, have previously been published in abstract form; yet, both the method and the results were insufficiently described. ${ }^{18}$ Our model has several advantages compared to the ovine model previously reported. First, the pig's abdominal anatomy is very similar to that of man, which makes the pig a good reference model for later human studies. Second, pigs are a cheaper alternative to sheep, especially in Denmark where the swine industry is extensive.

The main limitation of this study is the small number of animals. Only four pigs were followed through 6 weeks. It would have been desirable to use more animals to obtain statistical validity. A transvaginal approach would have been less invasive and would have reduced the operative risks. However, due to the narrowness of the vagina in pigs, this was not considered possible. It might also have been desirable to allow a longer follow-up period than 6 weeks or to use histological analysis to determine sufficient healing of the fistula tracts.

It is considered a major strength that all four pigs were of the same age, similar weight, and brought up in the same environment. This reduces the inter-individual differences and makes the pigs more comparable. The same, experienced urologist performed all operations, which avoids the potential bias of different surgical techniques and skills.

The low rate of VVF repair in Denmark makes VVF a surgical challenge and increases the risk of operative complications. ${ }^{11}$ Because of this and in view of the burden for the individual woman, safer and less invasive treatments for VVFs should be found. As mentioned earlier, stem cells could prove a promising treatment modality.

\section{Conclusion}

This study indicates that our model of VVF can prove to be an effective and cheap way to create fistulas between the bladder and the vagina. However, further studies with longer ureteral stents are necessary to prove the value of the model.

\section{Disclosure}

The authors report no conflicts of interest in this work.

\section{References}

1. Rovner ES. Urinary Tract Fistula. In: Louis R Kavoussi ACN, Alan W Partin, Craig A Peters, Alan J Wein, editors. Campbell-Walsh Urology. 3. 9 ed. Philadelphia, PA: Saunders Elsevier; 2007:2322-2341.

2. Tebeu PM, Fomulu JN, Khaddaj S, de Bernis L, Delvaux T, Rochat CH. Risk factors for obstetric fistula: a clinical review. Int Urogynecol J. 2012;23(4):387-394.

3. Cohen BL, Gousse AE. Current techniques for vesicovaginal fistula repair: surgical pearls to optimize cure rate. Curr Urol Rep. 2007;8(5): 413-418.

4. Langkilde NC, Pless TK, Lundbeck F, Nerstrom B. Surgical repair of vesicovaginal fistulae - a ten-year retrospective study. Scand J Urol Nephrol. 1999;33(2):100-103.

5. Duong TH, Gellasch TL, Adam RA. Risk factors for the development of vesicovaginal fistula after incidental cystotomy at the time of a benign hysterectomy. Am J Obstet Gynecol. 2009;201(5):512. e1-e4.

6. Hilton P, Cromwell DA. The risk of vesicovaginal and urethrovaginal fistula after hysterectomy performed in the English National Health Service - a retrospective cohort study examining patterns of care between 2000 and 2008. BJOG. 2012;119(12):1447-1454.

7. Forsgren C, Lundholm C, Johansson AL, Cnattingius S, Altman D. Hysterectomy for benign indications and risk of pelvic organ fistula disease. Obstet Gynecol. 2009;114(3):594-599.

8. Waaldijk K, Armiya'u YD. The obstetric fistula: A major public health problem still unsolved. Int Urogynecol J. 1993;4(2):126-128.

9. globalfistulamap.org [homepage on the Internet]. Direct Relief; 2011. [updated August 27, 2013; cited November 28, 2013]. Available from: http://www.globalfistulamap.org. Accessed June 13, 2015.

10. Harkki-Siren P, Sjoberg J, Tiitinen A. Urinary tract injuries after hysterectomy. Obstet Gynecol. 1998;92(1):113-118.

11. ssi.dk [homepage on the Internet]. Health Care Data and IT. Operations distributed by municipality. State Serum Institute: National Patient Registry; 2013 [updated July 26, 2013; cited November 27, 2013]. Available from: http://www.ssi.dk. Accessed June 13, 2015.

12. Sotelo R, Moros V, Clavijo R, Poulakis V. Robotic repair of vesicovaginal fistula (VVF). BJU Int. 2012;109(9):1416-1434.

13. Pastides P, Chimutengwende-Gordon M, Maffulli N, Khan W. Stem cell therapy for human cartilage defects: A systematic review. Osteoarthritis Cartilage. 2013;21(5):646-654.

14. Hou J, Wang L, Jiang J, et al. Cardiac stem cells and their roles in myocardial infarction. Stem Cell Rev. 2013;9(3):326-338.

15. Dabiri G, Heiner D, Falanga V. The emerging use of bone marrowderived mesenchymal stem cells in the treatment of human chronic wounds. Expert Opin Emerg Drugs. 2013;18(4):405-419.

16. Abreu SC, Antunes MA, Pelosi P, Morales MM, Rocco PR. Mechanisms of cellular therapy in respiratory diseases. Intensive Care Med. 2011; 37(9):1421-1431.

17. retsinformation.dk [homepage on the Internet]. Legal information. Announcement about Laboratory Animal Science, LBK nr 253. Fødevarestyrelsen; 2013 [updated March 15, 2013; cited November 27, 2013]. Available from: http://www.retsinformation.dk. Accessed June 13, 2015.

18. Crawford B, Zanjani E, Thain D, Stanford E, Van Andel R, Pixley J, et al. Ovine model of obstetric fistula. Neurourol Urodyn. 2009;28(7): 905-906.
Research and Reports in Urology

\section{Publish your work in this journal}

Research and Reports in Urology is an international, peer-reviewed, open access journal publishing original research, reports, editorials, reviews and commentaries on all aspects of adult and pediatric urology in the clinic and laboratory including the following topics: Pathology, pathophysiology of urological disease; Investigation and treatment of

\section{Dovepress}

urological disease; Pharmacology of drugs used for the treatment of urological disease. The manuscript management system is completely online and includes a very quick and fair peer-review system, which is all easy to use. Visit http://www.dovepress.com/testimonials.php to read real quotes from published authors. 